
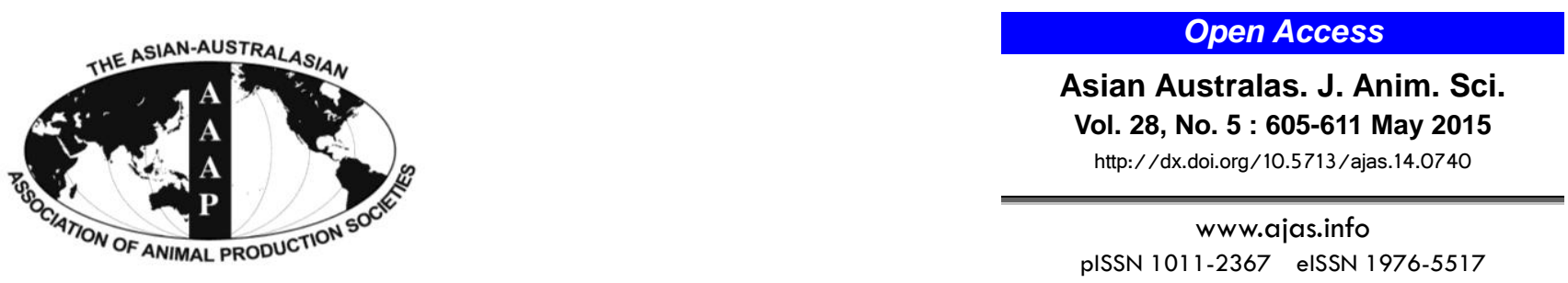

\title{
Selection for Duration of Fertility and Mule Duck White Plumage Colour in a Synthetic Strain of Ducks (Anas platyrhynchos)
}

\author{
H. C. Liu, J. F. Huang, S. R. Lee, H. L. Liu ${ }^{1}$, C. H. Hsieh ${ }^{1}$, C. W. Huang ${ }^{2}$, M. C. Huang ${ }^{3}$, C. Tai ${ }^{4}$, \\ J. P. Poivey ${ }^{5}$, R. Rouvier ${ }^{6}$, and Y. S. Cheng ${ }^{1, *}$ \\ Ilan Branch, Livestock Research Institute, Council of Agriculture, Ilan 26845, Taiwan
}

\begin{abstract}
A synthetic strain of ducks (Anas platyrhynchos) was developed by introducing genes for long duration of fertility to be used as mother of mule ducklings and a seven-generation selection experiment was conducted to increase the number of fertile eggs after a single artificial insemination (AI) with pooled Muscovy semen. Reciprocal crossbreeding between Brown Tsaiya LRI-2 (with long duration of fertility) and Pekin L-201 (with white plumage mule ducklings) ducks produced the G0. Then G1 were intercrossed to produce G2 and so on for the following generations. Each female duck was inseminated 3 times, at 26, 29, and 32 weeks of age. The eggs were collected for 14 days from day 2 after AI. Individual data regarding the number of incubated eggs (Ie), the number of fertile eggs at candling at day 7 of incubation (F), the total number of dead embryos (M), the maximum duration of fertility (Dm) and the number of hatched mule ducklings $(\mathrm{H})$ with plumage colour were recorded. The selection criterion was the breeding values of the best linear unbiased prediction animal model for F. The results show high percentage of exhibited heterosis in G2 for traits to improve ( $19.1 \%$ for F and $12.9 \%$ for $\mathrm{H}$ ); F with a value of 5.92 (vs 3.74 in the Pekin L-201) was improved in the G2. Heritabilities were found to be low for Ie $\left(h^{2}=0.07 \pm 0.03\right)$ and $\mathrm{M}\left(h^{2}=0.07 \pm 0.01\right)$, moderately low for $\mathrm{Dm}\left(h^{2}=0.13 \pm 0.02\right)$, of medium values for $\mathrm{H}\left(h^{2}=\right.$ $0.20 \pm 0.03)$ and $\mathrm{F}\left(h^{2}=0.23 \pm 0.03\right)$. High and favourable genetic correlations existed between $\mathrm{F}$ and $\mathrm{Dm}\left(\mathrm{r}_{\mathrm{g}}=0.93\right)$, between $\mathrm{F}$ and $\mathrm{H}\left(\mathrm{r}_{\mathrm{g}}\right.$ $=0.97)$ and between $\mathrm{Dm}$ and $\mathrm{H}\left(\mathrm{r}_{\mathrm{g}}=0.90\right)$. The selection experiment showed a positive trend for phenotypic values of $\mathrm{F}(6.38$ fertile eggs in G10 of synthetic strain vs 5.59 eggs in G4, and 3.74 eggs in Pekin L-201), with correlated response for increasing H (5.73 ducklings in G10 vs 4.86 in G4, and 3.09 ducklings in Pekin L-201) and maximum duration of the fertile period without increasing the embryo mortality rate. The average predicted genetic response for $\mathrm{F}$ was $40 \%$ of genetic standard deviation per generation of selection. The mule ducklings' feather colour also was improved. It was concluded that this study provided results for a better understanding of the genetics of the duration of fertility traits in the common female duck bred for mule and that the selection of a synthetic strain was effective method of improvement. (Key Words: Duck, Duration of Fertilization, Fertility, Selection, Plumage Colour)
\end{abstract}

\section{INTRODUCTION}

Mule duck meat production is developing in Europe,

\footnotetext{
* Corresponding Author: Y. S. Cheng. Tel: +886-6-5911211, Fax: +886-65912452, E-mail: yushin@ mail.tlri.gov.tw

${ }^{1}$ Livestock Rescarch Institute, Council of Agriculture, Tainan 71246, Taiwan.

${ }^{2}$ Department of Aquaculture, National Taiwan Ocean University, Keelung 20024, Taiwan.

${ }^{3}$ Department of Animal Science, National Chung Hsing University, Taichung 40227, Taiwan.

${ }^{4}$ Southern Taiwan University of Science and Technology, Tainan 71005, Taiwan.

${ }^{5}$ Institut National de la Recherche Agronomique, Station d'Amélioration Génétique des Animaux, 31326 Castanet-Tolosan, France.

${ }^{6}$ Institut National de la Recherche Agronomique, F-34000 Montpellier, France.

Submitted Sept. 22, 2014; Revised Oct. 23, 2014; Accepted Nov. 8, 2014
}

Vietnam and South East China (Cheng et al., 2009). The mule ducks are sterile intergeneric hybrids which are produced by crossing Pekin or Kaiya (crossbred Pekinx White Tsaiya) female ducks with Muscovy drakes (Cairina moschata). The reproductive efficiency was dramatically improved over the last 25 years by using artificial insemination (AI). However, the AI has to be practiced twice a week and the fertility rate was lower than in parental lines pure breeding (Brun and Larzul, 2003; Sellier et al., 2005). The duration of the fertile period was defined by Lake (1975) as the time lag between AI and the last fertile egg laid. A long-term selection experiment, using the number of fertile eggs (F) (at candling at 7th day after egg set) after a single AI of Brown Tsaiya female duck with pooled Muscovy semen as the selection trait began in 1992 
(Cheng, 1995). Cheng et al. (2002; 2005; 2009) demonstrated that selection to increase duration of fertility in the Brown Tsaiya LRI 2 (BT LRI-2) was possible. It was suggested that selection on $\mathrm{F}$ acted by increasing the storage capacity of spermatozoa at the utero vaginal junction, which remained able to fertilize the ova longer. DNA microarray technology was used for the studies on differentially expressed genes associated with reproductive performance in Tsaiya ducks in Taiwan and the genotypes for markerassisted selection were also investigated (Huang et al., 2011a,b; 2013; Chang et al., 2012a,b; 2013). To identify genes or markers related to duration of fertility in ducks, a quantitative trait locus experiment with a F2 design used the ducks of the BT LRI-2 and of I-Lan Pekin L-201 (Pekin L201) as G0, the G1 being produced by reciprocal crossbreeding (Huang, 2007). The duck (Anas platyrhynchos) genetic linkage map of amplified fragment length polymorphism markers has been established (Huang et al., 2009). We took advantages of the existence of this G2 to build a synthetic strain, to be used as mother of mule ducks, by introducing genes for high duration of fertility. This study investigated phenotypic variability, heterosis, estimates of genetic parameters and predicted genetic responses for $\mathrm{F}$ in a synthetic strain of ducks selected with purpose of increasing the number of fertile eggs after single AI with pooled Muscovy semen, and for producing white plumage mule ducks.

\section{MATERIALS AND METHODS}

\section{Ducks and experimental design}

The BT LRI-2 in the 10th generation (G10) of the selection experiment on the duration of fertility (Cheng et al., 2009) and the Pekin L-201 were chosen to give the G0 breeding animals. The Pekin L-201 was used to produce Kaiya female ducks by crossbreeding with White Tsaiya. In the G0, 3 BT LRI-2 drakes were each crossbred with 2 Pekin female ducks of Pekin L-201 (TxP). Three Pekin drakes of Pekin L-201 were each crossbred with 2 BT LRI2 female ducks $(\mathrm{P} \times \mathrm{T})$. For the mating of $\mathrm{G} 1 \times \mathrm{G} 1$, three drakes G1 from the three sire BT LRI-2 and dam Pekin L201 were each crossbred with six unrelated female duck progeny of sire BT LRI-2 and dam Pekin L-201. Three drakes G1 from three sire Pekin L-201 and dam BT LRI-2 were crossbred with unrelated female ducks progeny of sire Pekin L-201 and dam BT LRI-2. From G2, male and female ducks of successive generations were produced by intermating selected male and females in each generation. Pedigree hatching was conducted in each generation and an individual recording system was used. Supplementary Table $\mathrm{S} 1$ shows the experimental population for crossbreeding in the synthetic strain (G1 and G2) and the selection on the duration of fertility from G3 up to G10. A total of 2,541 females and 1,030 males were raised and evaluated. The males were evaluated on the performances $(F)$ of relatives. Full-sib and half-sib matings were avoided. In G10, the means \pm standard deviation (SD) of the inbreeding coefficients were $0.166 \pm 0.024$ for the males and $0.164 \pm 0.023$ for the females respectively (Supplementary Table S2). From G2, G4 to G10 female ducks at 26, 29, and $32 \mathrm{wk}$ of age were artificially inseminated with $0.05 \mathrm{~mL}$ of pooled semen from 10 to 15 Muscovy drakes of line 302 (Tai and Tai, 1991). After a single AI, eggs were collected for a period of 14 days (from day 2 to 15) and incubated for each 7 days for G2, G4 up to G10. Fertility was determined by candling the eggs after 7 days of incubation, and hatchability was measured. The same fertility tests were done on Pekin L-201 ducks in three successive generations in 2006, 2007, and 2009, the eggs being collected for a period of 14 days (day 2 to 15). Data regarding the number of eggs set (Ie), F, the total number of dead embryos (M), the maximum duration of fertility (Dm) measured as the time lag between first and last fertile egg laid and the number of hatched mule ducklings $(\mathrm{H})$ were recorded. The management of ducklings and laying ducks was similar since Cheng et al. (2009). The animal used protocol listed previously has been reviewed and approved by the Institutional Animal Care and Use Committee of Livestock Research Institute.

\section{Statistical analysis}

The parameters of elementary statistics (means and variances) of phenotypic values were obtained using the SAS procedure (SAS, 1996). Heterosis in G2 was calculated as the difference between G2 means and parent populations of G1 means. The variance components were estimated from G4 to G10 pedigree data and performance pooled data. Data were analyzed in a multitrait animal model, the same model as in Poivey et al. (2001), in conjunction with the restricted maximum likelihood methodology and using the VCE package developed by Groeneveld (1996).

\section{Selected strain}

In the synthetic strain, from G3 male and female ducks in each generation were selected by truncation on superior values of the best linear unbiased prediction (BLUP) animal model for $\mathrm{F}$ from the 2 nd to the 15 th day after AI (3 replications). The model for the prediction of additive genetic values of the selected trait was as described in Cheng et al. (2002) the following.

$$
\begin{aligned}
& y=X b+Z_{1} a+Z_{2} p+e \\
& \text { where } \\
& y=\text { the vector of observations; }
\end{aligned}
$$


$b=$ the vector of fixed effects of hatching date;

$\mathrm{a}=$ the vector of random genetic effects with $\mathrm{E}(\mathrm{a})=0$, $\operatorname{Var}(\mathrm{a})=\mathrm{A} \sigma_{a}^{2}$, where

$\mathrm{A}$ is the additive genetic relationship matrix of the animals,

$\sigma_{a}^{2}=$ the additive genetic (co)-variances;

$\mathrm{p}=$ the vector of random repeat effects with $\mathrm{E}(\mathrm{p})=0$, $\operatorname{Var}(\mathrm{p})=\mathrm{I} \sigma_{p}^{2}$, where

I is the identity matrix, $\sigma_{p}^{2}=$ the (co)-variances of repeat effects;

$\mathrm{e}=$ the vector of random residual effects with $\mathrm{E}(\mathrm{e})=0$, $\operatorname{Var}(\mathrm{e})=\mathrm{I} \sigma_{e}^{2}$, where

$\sigma_{e}^{2}=$ the (co)-variances of random residual effects;

$\mathrm{X}, \mathrm{Z}_{1}$, and $\mathrm{Z}_{2}=$ the matrices relating the elements of $\mathrm{b}, \mathrm{a}$, and $\mathrm{p}$ to the observations.

Breeding values were evaluated in each generation for each trait by BLUP using a mixed linear model with the PEST package (Groeneveld, 1990) with the same model described above. For each generation, an additive genetic relationship matrix was established by taking into account all the ancestors of the selection candidates back to the foundation stock (G3). Duck performance in all generations (from G4 to G10) was also taken into account. The predicted genetic responses to selection on $\mathrm{F}$ was estimated from G3 up to G10 by the average predicted breeding values for each generation in female ducks.

\section{Plumage grading}

Mule ducklings were graded to one of 15 classes depending on the area of black spot of plumage according to the plumage grading standard set by Lee et al. (1993). From G3 male and female ducks in each generation were selected according to the highest values of predictors of breeding values of $\mathrm{F}$ and the average of feather grade of mule ducklings.

\section{RESULTS AND DISCUSSION}

The results of five traits for reciprocal crossbred progeny showed favourable grand-maternal effect of Pekin L-201 versus BT LRI-2 ducks. The selected trait F, was $6.20 \pm 2.04$ and $5.59 \pm 1.98$ in the $(\mathrm{T} \times \mathrm{P}) \times(\mathrm{T} \times \mathrm{P})$ and $(\mathrm{P} \times \mathrm{T}) \times$ $(\mathrm{P} \times \mathrm{T}) \mathrm{G} 2$ progeny, respectively. However, performances of the traits $\mathrm{Dm}, \mathrm{H}$, and $\mathrm{M}$ of $(\mathrm{T} \times \mathrm{P}) \times(\mathrm{T} \times \mathrm{P})$ still remained much higher than that of $(\mathrm{P} \times \mathrm{T}) \times(\mathrm{P} \times \mathrm{T})$ in $\mathrm{G} 2$ progeny of reciprocal crossbred (Liu et al., 2010). Thereafter, 10 sires and 27 dams of white or black spot feather colours of G2 with the highest predictors of breeding values were mated between themselves to produce next generation. A similar procedure was applied for the following generations. Table 1 shows the means and SD for Ie, F, M, Dm, and H for all records obtained from G4 to G10. The skewness and kurtosis coefficients were calculated, and according to the values of these coefficients the distributions of $\mathrm{F}, \mathrm{H}$, and Dm showed small discrepancies from normality; these discrepancies were significant for Ie. Since the number of eggs set were recorded every $14 \mathrm{~d}$ in each repetition, it also explains the skewness and kurtosis of Ie. Tai et al. (1994) and Cheng (1995) found that the discrepancies from normality were small according to the kurtosis and skewness coefficients for F, H, and Dm, slightly larger for $\mathrm{M}$ and larger yet for Ie with a distribution of the number of eggs per batch between 13 and 14. Table 2 gives the means and SD of the five traits for G10 of the BT LRI-2, Pekin L201 (averages of three generations in 2006, 2007, and 2009), G2, G4 to G10 of the synthetic strain and h \% estimated percent of heterosis in G2. High percentage of exhibited heterosis for traits to improve $(5.6 \%$ for Ie, $19.1 \%$ for $\mathrm{F}$ and $12.9 \%$ for $\mathrm{H}$ ) was favourable for building the synthetic strain. F with a value of 5.92 (vs 3.74 in Pekin L-201) was improved in the G2, G8 (6.52), and up to G10 (6.38).

The fertility rate in days 2 to 8 after AI was $79.1 \%$ in the G2, $86.1 \%$ at G8 and $80.3 \%$ for G10. Rouvier et al. (1984) showed the range from $63 \%$ to $83 \%$ (average $71 \%$ ) on 220,000 eggs of Kaiya ducks (crossbred Pekin $\times$ White Tsaiya) inseminated twice a week with mixed semen of Muscovy drakes resulting from three Taiwanese farms. There was no significant phenotypic trend for F between G4 and $\mathrm{G} 7$, but there was a positive phenotypic trend between G7 and G10 where F was superior to its value in BT LRI-2 (G10) (6.38 vs 6.20). There was a tremendous increase in $\mathrm{H}$ in the G2 (4.30 vs 3.09 in Pekin L-201) which accumulated half of the direct heterosis maintained in G2 and maternal heterosis. The new increase of $\mathrm{H}$ in G4, G5, and up to G10 compared to G2 was explained by a favourable hatch effect and a better hatchability. There was also increase in Dm in the G2 (7.06 vs 4.62 in Pekin L-201) and up to G10 (7.91). There was no evidence of increasing embryo mortality when $\mathrm{F}$ was increasing.

\section{Estimation of genetic parameters}

In order to calculate predicted breeding values it was

Table 1. Means, phenotypic standard deviation (SD), skewness and kurtosis of the five traits for synthetic strain of ducks from records $(\mathrm{n})^{1}$ of generation 4 to 10

\begin{tabular}{lccccc}
\hline Trait $^{2}$ & Means & SD & Range & Skewness & Kurtosis \\
\hline $\mathrm{Ie}$ & 13.16 & 1.55 & $6-15$ & -2.36 & 5.77 \\
$\mathrm{~F}$ & 5.93 & 2.01 & $1-12$ & -0.26 & -0.22 \\
$\mathrm{M}$ & 0.79 & 0.94 & $0-7$ & 1.29 & 1.90 \\
$\mathrm{Dm}$ & 7.35 & 2.19 & $1-14$ & -0.15 & 0.20 \\
$\mathrm{H}$ & 5.14 & 2.02 & $0-11$ & -0.18 & -0.27 \\
\hline
\end{tabular}

${ }^{1} \mathrm{n}$, number of records of measured female ducks, total 4,517 for G4-G10. ${ }^{2}$ Ie, number of eggs set; F, number of fertile eggs at candling (7th day of incubation); $\mathrm{M}$, total number of dead embryos; Dm, maximum duration of fertility; $\mathrm{H}$, number of hatched mule ducklings. 
Table 2. The means and standard deviation (SD) of the five traits for G10 of the Brown Tsaiya (BT LRI-2) selected line, Pekin L-201 (averages of three generations in 2006, 2007, and 2009), G2, G4 to G10 of synthetic strain of ducks

\begin{tabular}{lccccccccccc}
\hline Trait $^{1}$ & $\begin{array}{c}\text { BT LRI-2 } \\
(\mathrm{G} 10) \\
(\mathrm{n}=555)\end{array}$ & $\begin{array}{c}\text { Pekin } \\
\mathrm{L}-201 \\
(\mathrm{n}=826)\end{array}$ & $\begin{array}{c}\mathrm{G} 2 \\
(\mathrm{n}=1,351)\end{array}$ & $\mathrm{h} \%{ }^{2}$ & $\begin{array}{c}\mathrm{G} 4 \\
(\mathrm{n}=657)\end{array}$ & $\begin{array}{c}\mathrm{G} 5 \\
(\mathrm{n}=667)\end{array}$ & $\begin{array}{c}\mathrm{G} 6 \\
(\mathrm{n}=530)\end{array}$ & $\begin{array}{c}\mathrm{G} 7 \\
(\mathrm{n}=650)\end{array}$ & $\begin{array}{c}\mathrm{G} 8 \\
(\mathrm{n}=696)\end{array}$ & $\begin{array}{c}\mathrm{G} 9 \\
(\mathrm{n}=577)\end{array}$ & $\begin{array}{c}\mathrm{G} 10 \\
(\mathrm{n}=740)\end{array}$ \\
\hline $\mathrm{Ie}$ & 14.42 & 12.31 & 14.11 & 5.6 & 13.70 & 13.69 & 13.74 & 13.19 & 12.75 & 12.17 & 12.91 \\
& $(3.95)$ & $(2.49)$ & $(1.51)$ & & $(1.24)$ & $(1.24)$ & $(1.10)$ & $(1.43)$ & $(1.46)$ & $(1.91)$ & $(1.65)$
\end{tabular}

F $\quad 6.20(2.38) \quad 3.74(1.63) \quad 5.92(1.98) \quad 19.1 \quad 5.59(1.98) 5.98(2.01) 5.66(1.80) 5.63(2.04) 6.52(1.91) 5.56(1.96) 6.38(2.07)$

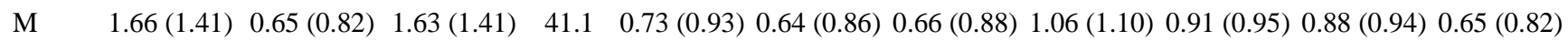

$\mathrm{Dm} \quad 7.62(2.67) \quad 4.62(1.74) 7.06(2.10) \quad 15.4 \quad 6.84(2.18) 7.22(2.13) 6.85(2.05) 7.04(2.21) 8.19$ (2.05) $7.15(2.24) 7.91(2.06)$

$\mathrm{H} \quad 4.53(2.30) \quad 3.09(1.66) \quad 4.30(1.95) \quad 12.9 \quad 4.86(2.01) 5.34(2.00) 5.00(1.86) 4.58(1.94) 5.61(1.90) 4.69(2.00) 5.73(2.06)$

n, number of observations.

${ }^{1}$ Ie, number of eggs set; F, number of fertile eggs at candling (7th day of incubation); M, total number of dead embryos; Dm, maximum duration of fertility; $\mathrm{H}$, number of hatched mule ducklings.

${ }^{2} \mathrm{~h} \%$ direct heterosis measured in $\mathrm{G} 2$.

necessary to estimate the genetic parameters in the synthetic strain. Heritabilities, genetic correlations, phenotypic correlations and repeatabilities (r), computed among the estimated variance components, are given in Table 3. Heritabilities were found to be low for Ie $\left(h^{2}=0.07 \pm 0.03\right)$ and $\mathrm{M}\left(h^{2}=0.07 \pm 0.01\right) ; \mathrm{Dm}\left(h^{2}=0.13 \pm 0.02\right), \mathrm{H}\left(h^{2}=\right.$ $0.20 \pm 0.03)$ and $\mathrm{F}\left(h^{2}=0.23 \pm 0.03\right)$ had moderately low to medium heritability. High and favourable genetic correlations existed between $\mathrm{F}$ and $\mathrm{Dm}\left(\mathrm{r}_{\mathrm{g}}=0.93\right)$, between $\mathrm{F}$ and $\mathrm{H}\left(\mathrm{r}_{\mathrm{g}}=0.97\right)$ and between Dm and $\mathrm{H}\left(\mathrm{r}_{\mathrm{g}}=0.90\right)$. The genetic correlation between $\mathrm{F}$ and $\mathrm{H}$ is high and indirect selection of $\mathrm{H}$ by selecting on $\mathrm{F}$ should be as efficient as or better than direct selection. These were very close to previous estimations of the genetic parameters in the base population of the BT LRI-2 and unselected control lines (Poivey et al., 2001) and of the Pekin L-201 ducks selected line (Liu et al., 2013). Selection on additive genetic values of $\mathrm{F}$ seems to be possible in this synthetic strain. The selection method on breeding values should avoid full-sib and half-sib matings and also should control the increase of inbreeding in order to avoid inbreeding depression.

Phenotypic correlations and repeatabilities, computed among the estimated variance components, are given in Table 3. The five traits have moderately low to medium repeatabilities (between 0.14 and 0.38 ), $\mathrm{F}$ had significantly higher positive phenotypic correlation with $\mathrm{Dm}$ and $\mathrm{H}\left(\mathrm{r}_{\mathrm{p}}=\right.$
0.74; $\left.r_{p}=0.89\right)$, than with Ie and $M\left(r_{p}=0.20 ; r_{p}=0.22\right) . H$ had medium to high positive correlation with Ie and Dm $\left(\mathrm{r}_{\mathrm{p}}\right.$ $\left.=0.22 ; r_{p}=0.63\right)$, and had medium negative correlation with $M\left(r_{p}=-0.24\right)$. $M$ had positive correlation with Dm $\left(r_{p}\right.$ $=0.22$ ). There were very small negative correlation between $\mathrm{Ie}, \mathrm{M}$, and $\mathrm{Dm}\left(\mathrm{r}_{\mathrm{p}}=-0.05 ; \mathrm{r}_{\mathrm{p}}=-0.02\right)$.

\section{Phenotypic trends and predicted genetic response}

The analysis of phenotypic trends of the selection experiment after 7 generations of selection showed a positive trend for phenotypic values of $F$ (6.38 in G10 versus 5.59 eggs in G4 of selected synthetic strain), with correlated response for increasing $\mathrm{H}(5.73$ vs 4.86 ducklings) and maximum duration of the fertile period (7.91 vs 6.84 days), without increasing the embryo mortality rate ( 0.65 dead embryos in G10 vs 0.73 dead embryos in G4) (Table 2). Figure 1 gives the adjusted logistic curves of fertility rate according to the number of days after AI for the BT LRI-2 (G1, G10) and the synthetic strain (G2, G10). In the synthetic strain (G10), fertility rates were $91 \%$ at $\mathrm{d} 2$, higher than $85 \%$ from d3 to d5. From d6 (79\%) onwards they began to decrease to $\mathrm{d} 7(72 \%), \mathrm{d} 8(59 \%)$ and $1 \%$ on d14. Consequently, the largest increase of the per day fertility rates after AI were between d6 and d12. The same tendencies were observed for the changes in synthetic strain, showing that after 7 generations of selection the adjusted

Table 3. Heritabilities (on diagonal), genetic correlations (above the diagonal), \pm standard errors of estimates, phenotypic correlations (below the diagonal) and repeatabilities (r) for the Ie, F, M, Dm, and H traits, estimated in the base population from the data of G4 to G10 synthetic strain of ducks

\begin{tabular}{lcccccc}
\hline & $\mathrm{Ie}$ & $\mathrm{F}$ & $\mathrm{M}$ & $\mathrm{Dm}$ & $\mathrm{H}$ & Repeatabilities $(\mathrm{r})$ \\
\hline $\mathrm{Ie}$ & $0.07 \pm 0.03$ & $0.39 \pm 0.14$ & $0.50 \pm 0.17$ & $0.12 \pm 0.18$ & $0.23 \pm 0.17$ & 0.31 \\
$\mathrm{~F}$ & $0.20^{* *}$ & $0.23 \pm 0.03$ & $0.40 \pm 0.11$ & $0.93 \pm 0.02$ & $0.97 \pm 0.01$ & 0.38 \\
$\mathrm{M}$ & $-0.05^{* *}$ & $0.22^{* *}$ & $0.07 \pm 0.01$ & $0.32 \pm 0.13$ & $0.17 \pm 0.13$ & 0.14 \\
$\mathrm{Dm}$ & -0.02 & $0.74 * *$ & $0.22^{* *}$ & $0.13 \pm 0.02$ & $0.90 \pm 0.03$ & 0.26 \\
$\mathrm{H}$ & $0.22^{* *}$ & $0.89^{* *}$ & $-0.24 * *$ & $0.63 * *$ & $0.20 \pm 0.03$ & 0.35 \\
\hline
\end{tabular}

Ie, number of eggs set; F, number of fertile eggs at candling (7th day of incubation); M, total number of dead embryos; Dm, maximum duration of fertility; $\mathrm{H}$, number of hatched mule ducklings. $* * \mathrm{p}<0.01$. 


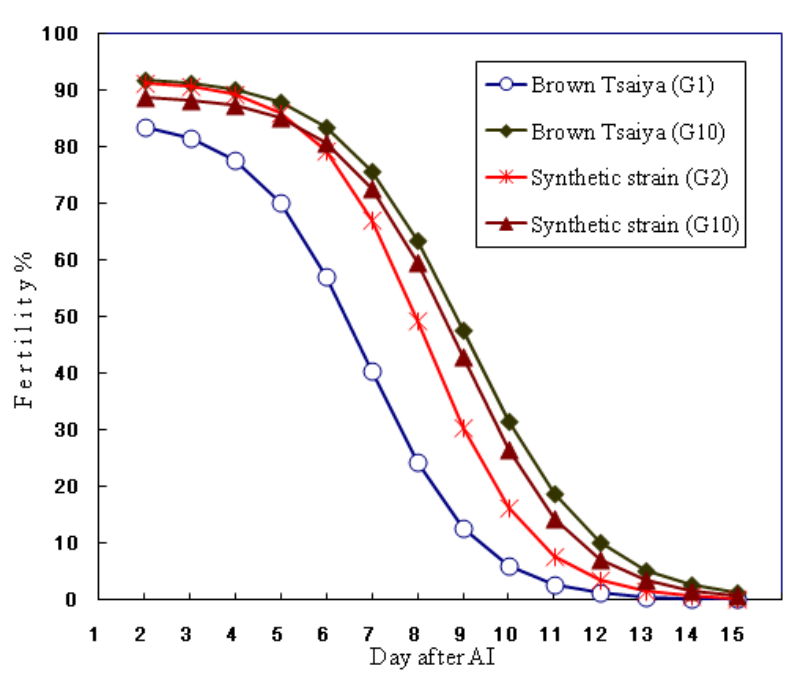

Figure 1. Duration of fertility after single artificial insemination (AI) with pooled Muscovy semen of selected G1, G10 of Brown Tsaiya lines (BT LRI-2) and G2, G10 of synthetic strain. Solid lines represent the functions of logistic curves $y(x)=91.90 / 1+e-$ $0.8471(8.182-\mathrm{x})$ for the $\mathrm{G} 2$ and $\mathrm{y}(\mathrm{x})=89.18 / 1+\mathrm{e}-0.7830(8.9073-$ $\mathrm{x})$ for the G10 of synthetic strain.

logistic curves of fertility rate were very close to the BT LRI-2 (G10).

The predicted genetic response for $\mathrm{F}$ in the synthetic strain across generations from G4 up to G10 was 2.74 eggs (Figure 2). It was 2.8 genetic standard deviation $(2.74 / 0.979)$ in total or $40 \%$ of the genetic standard deviation per generation. The result is consistent with the genetic parameters and very close to results obtained in the BT LRI-2 (Cheng et al., 2009).

\section{Mule duck plumage colour}

Farmers used black Muscovy drakes mated with Brown Tsaiya female ducks as parental stock to produce mule ducks since 17 th century to mid 20th century, and the AI technique has been applied for the production of mule ducks in Taiwan (Chou and Huang, 1970; Tai and Tai, 1989). Later, the mule duck has been produced in three way crossing (white Muscovy drakexKaiya [Pekin drakexWhite Tsaiya]). Due to the demand for white mule ducks, a criterion of fifteen colour levels of mule ducklings' down has been used since 1966 to select White Tsaiya ducks. The realized heritability of white mule duck's plumage colour estimated from the selection data from 1976 to 1982 was calculated as 0.38 (Huang, 1985). The selection of White Tsaiya of generation 16 has reached its goal with $99.8 \%$ of mule ducks better than grade 7; and $99.5 \%$ better than grade 7 was observed in Pekin L-201 ducks of generation 14. The grade 7 is the lowest level accepted by farmers (Lee and Kang, 1997). When we calculated the mule ducklings plumage grade of each generation in the synthetic strain, the

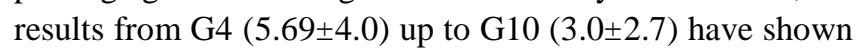

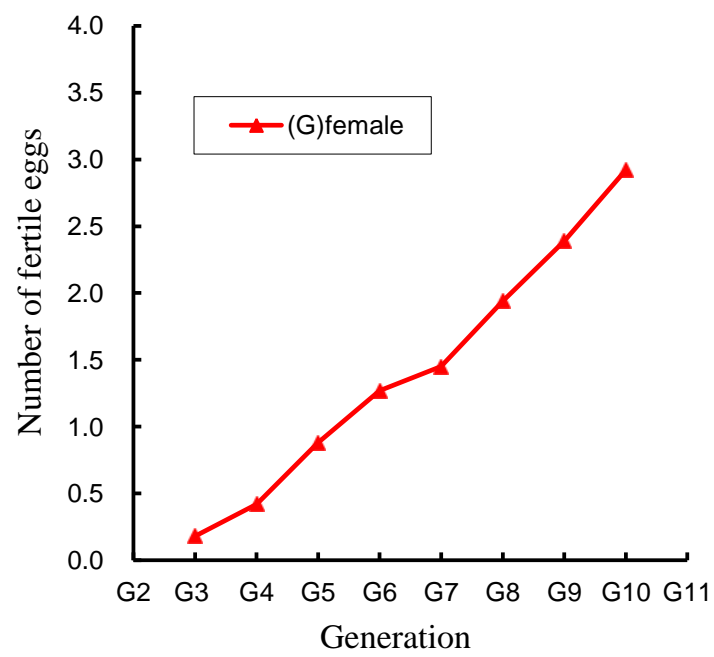

Figure 2. Predicted genetic (G) response for the number of fertile eggs at candling across 7 generations of selection in synthetic strain female ducks.

improvement (Supplementary Table S3). The feather grade of mule ducklings was effectively improved from G4 to G10 after male and female ducks of each generation were selected according to the average of feather grade of mule ducklings. It was found that $72 \%$ mule ducklings feathers of G4 and $96 \%$ of G10 were equal or lesser than grade 7 , and that $19 \%$ mule ducklings feathers of G4 and $61 \%$ of G10 were equal or lesser than grade 3 (Table 4). The improvement of feather grade of mule ducklings may result from increasing homozygosity of genes other than $c$ transmitted by the Pekin L-201. This study provided results for a better understanding of the genetics of the duration of fertility traits in the common female duck bred for mule and that the selection of a synthetic strain was effective for their improvement both in the duration of fertility and mule offspring plumage.

\section{IMPLICATIONS}

It would be economically beneficial for mule duck production if the duration of the female duck fertile period could be lengthened and resulted in performing AI once

Table 4. Cumulative percentage in plumage grade of mule ducklings from G4 to G10 of the selected synthetic strain of duck

\begin{tabular}{lccccccc}
\hline \multirow{2}{*}{ Grade } & \multicolumn{7}{c}{ Cumulative $(\%)$} \\
\cline { 2 - 8 } & G4 & G5 & G6 & G7 & G8 & G9 & G10 \\
\hline$\leq 1$ & 0 & 0 & 2 & 9 & 4 & 0 & 2 \\
$\leq 2$ & 8 & 6 & 14 & 39 & 40 & 34 & 52 \\
$\leq 3$ & 19 & 14 & 24 & 49 & 45 & 46 & 61 \\
$\leq 4$ & 34 & 28 & 34 & 60 & 59 & 60 & 71 \\
$\leq 5$ & 49 & 41 & 47 & 74 & 77 & 73 & 83 \\
$\leq 6$ & 61 & 59 & 56 & 81 & 86 & 82 & 90 \\
$\leq 7$ & 72 & 70 & 66 & 90 & 92 & 88 & 96 \\
\hline
\end{tabular}


instead of twice a week while maintaining fertility. Our experiment showed that reaching the objective of more than $84 \%$ of fertility after a single AI per week was realistic by selection of a synthetic strain of duck.

\section{ACKNOWLEDGMENTS}

This study was undertaken as a cooperative research project between the Council of Agriculture-Livestock Research Institute (COA-LRI), National Chung Hsing University (NCHU) and the Institut National de la Recherche Agronomique-Station d'Amélioration Génétique des Animaux du Département de Génétique Animale (INRA-SAGA). We would like to thank all the staff at LRI (especially Ilan Branch Institute of LRI for supplying Pekin and Muscovy ducks) and NCHU for their help in carrying out this research and also National Science Council (NSC 93-2313-B-061-003), COA-LRI for their financial support.

\section{REFERENCES}

Brun, J. M. and C. Larzul. 2003. Inheritance of reproductive traits of female common ducks (Anas platyrhynchos) in pure breeding and in inter-generic crossbreeding with Muscovy ducks (Cairina moschata). Br. Poult. Sci. 44:40-45.

Chang, M. T., Y. S. Cheng, and M. C. Huang. 2012a. The SNP genotypes of growth hormone gene associated with reproductive traits in Tsaiya ducks. Reprod. Domest. Anim. 47:568-573.

Chang, M. T., Y. S. Cheng, and M. C. Huang. 2012b. A novel nonsynonymous SNP of the COLX gene and its association with duck reproductive traits. Mol. Cell. Probes 26:204-207.

Chang, M. T., Y. S. Cheng, and M. C. Huang. 2013. Novel genetic markers of the carbonic anhydrase II gene associated with egg production and reproduction traits in Tsaiya ducks. Reprod. Domest. Anim. 48:98-104.

Cheng, Y. S. 1995. The Selection for the Egg Production and Duration of Fertility in Brown Tsaiya Bred in Intergeneric Crossbreeding with Muscovy Drakes. PhD. Thesis, Institut National Polytechnique de Toulouse, France.

Cheng, Y. S., R. Rouvier, J. P. Poivey, J. J. L. Tai, C. Tai, and S. C. Huang. 2002. Selection responses for number of fertile eggs of Brown Tsaiya duck (Anas platyrhynchos) after a single artificial insemination with pooled Muscovy (Cairina moschata) semen. Genet. Sel. Evol. 34:597-611.

Cheng, Y. S., R. Rouvier, J. P. Poivey, H. C. Huang, H. L. Liu, and C. Tai. 2005. Selection responses in duration of fertility and its consequences on hatchability in the intergeneric crossbreeding of ducks. Br. Poult. Sci. 46:565-571.

Cheng, Y. S., R. Rouvier, H. L. Liu, S. C. Huang, Y. C. Huang, C. W. Liao, J. J. L. Tai, C. Tai, and J. P. Poivey. 2009. Eleven generations of selection for the duration of fertility in the intergeneric crossbreeding of ducks. Genet. Sel. Evol. 41:32. (open access)

Chou, K. Y. and H. H. Huang. 1970. The duck industry in Taiwan. Chinese-American Joint Commission on Rural Reconstruction, Animal Industry Series no 8.
Groeneveld, E. 1990. PEST User's manual, Department of Animal Sciences. University of Illinois, Urbana, IL, USA.

Groeneveld, E. 1996. REML VCE a multivariate multimodel restricted maximum likelihood (co) variance estimation package. Version 4.2 User's Guide. Institute of Animal Husbandry and Animal Behaviour, FAL, Mariensee, Germany.

Huang, C. W. 2007. Construction of duck (Anas platyrhynchos) linkage maps by AFLP markers. Thesis PhD, National ChungHsing University, Taichung, Taiwan.

Huang, C. W., Y. S. Cheng, R. Rouvier, K. T. Yang, C. P. Wu, H. L. Huang, and M. C. Huang. 2009. Duck (Anas platyrhynchos) linkage mapping by AFLP fingerprinting. Genet. Sel. Evol. 41:28.

Huang, H. H. 1985. Selection of white mule ducks. J. Chin. Soc. Anim. Sci. 14:111-122.

Huang, H. L., Y. S. Cheng, C. W. Huang, M. C. Huang, and W. H. Hsu. 2011a. A novel genetic marker of the ovomucoid gene associated with hatchability in Tsaiya ducks (Anas platyrhynchos). Anim. Genet. 42:421-427.

Huang, H. L., Y. S. Cheng, K. T. Yang, C. H. Chen, M. C. Huang, and W. H. Hsu. 2011b. Genome-wide transcript expression analysis in the uterovaginal junction in association with fertile period in Tsaiya ducks. J. Reprod. Dev. 57:731-736.

Huang, H. L., L. T. Huang, and Y. S. Cheng. 2013. A novel SNP marker of ovalbumin gene in association with duck hatchability. Theriogenology 79:1218-1223.

Lake, P. E. 1975. Gamete production and the fertile period with particular reference to domesticated birds. Symp. Zool. Soc. 35:225-244.

Lee, S. R., Y. H. Yu, and M. C. Chen. 1993. Selection of parental lines of white mule ducks. J. Taiwan Livest. Res. 26:121-129.

Lee, S. R. and C. L. Kang. 1997. Improvement on percentage of white plumage in mule ducks. J. Taiwan Livest. Res. 30:293299.

Liu, H. C., S. R. Lee, H. L. Liu, C. H. Hsieh, C. W. Huang, M. C. Huang, C. Tai, J. P. Poivey, R. Rouvier, and Y. S. Cheng. 2010. Genetic parameters for the duration of fertility in a duck (Anas platyrhynchos) synthetic strain bred for mule ducks. In: Proceedings of the 14th AAAP Animal Science Congress, Pingtung, Taiwan. pp. 19.

Liu, H. C., Y. H. Hu, J. F. Huang, J. P. Poivey, R. Rouvier, and Y. S. Cheng. 2013. Genetic parameters for the duration of fertility in Pekin ducks (Anas platyrhynchos). In: Proceedings of the 5th World Waterfowl Conference. Hanoi, Vietnam. pp. 50-53.

Poivey, J. P., Y. S. Cheng, R. Rouvier, C. Tai, C. T. Wang, and H. L. Liu. 2001. Genetic parameters of reproductive traits in Brown Tsaiya ducks artificially inseminated with semen from Muscovy drakes. Poult. Sci. 80:703-709.

Rouvier, R., J. J. L. Tai, and C. Tai. 1984. Artificial insemination in common ducks for production of mule in Taiwan. The current situation-Artificial insemination and genetic improvement: Review and critical perspectives ToulouseAuzeville, France. pp. 360-367.

Statistical Analysis System Institute. 1996. SAS User's Guide Statistics. Version 6.12. SAS Institute Inc., Cary, NC, USA.

Sellier, N., J. M. Brun, M. M. Richard, F. Batellier, V. Dupuy, and J. P. Brillard. 2005. Comparison of fertility and embryo mortality following artificial insemination of common duck females (Anas platyrhynchos) with semen from common or 
Muscovy (Cairina moschata) drakes. Theriogenology 64:429439.

Tai, J. J. L. and C. Tai. 1989. Studies on the artificial insemination of ducks. In Proceeding of the Symposium on Animal Production in Taiwan in Celebrating the 30th Anniversary of Taiwan Livestock Research Institute, Tainan, Taiwan. pp. 171179.
Tai, J. J. L. and C. Tai. 1991. Mule duck production in Taiwan. I. Artificial insemination of ducks. Food and Technology Center, extension bulletin $\mathrm{n}^{\circ} 328: 1-6$

Tai, C., J. P. Poivey, and R. Rouvier. 1994. Heritabilities for duration of fertility traits in Brown Tsaiya female ducks (Anas platyrhynchos) by artificial insemination with pooled Muscovy (Cairina moschata) semen. Br. Poult. Sci. 35:59-64. 